\title{
The grand challenges to air pollution
}

\section{Costas A. Varotsos *}

Department of Environment Physics and Meteorology, Faculty of Physics, University of Athens, Athens, Greece

${ }^{*}$ Correspondence: covar@phys.uoa.gr

Edited by:

Yong Xue, London Metropolitan University, UK

Keywords: air pollutants, aerosols, atmosphere, clouds, remote sensing, climate impact, tropospheric ozone, stratosphere-troposphere connection

Several cultures emphasize that one should live in harmony with the environment, avoiding those human activities that substantially interfere with natural processes, including air pollution. Undoubtedly, the atmosphere is a principal environmental component, representing a crucial part of the entire climate system (Ayers, 2005). It behaves as a colloidal medium because it contains not only gases but also suspended particles and clouds.

In ancient times the term "air pollution" was represented by smoke and soot. For example, Horatius (classical poet 65 B.C. -8 A.D.) wrote that Roman buildings became more and more dark from smoke. According to Xenophon (434-359 B.C.) and Lucretius (98-55 B.C.), harmful smoke of lead mines in Attica were damaging to peoples' health. Since then, a huge amount of historical information and a large body of literature on this field has become available. It mainly concerns air pollution sources, air pollutants content, health effects, engineering, and policy (Kelly, 2003; Schwartz, 2004; Dockery and Stone, 2007; Miller et al., 2007; Wilson et al., 2007; Fullerton et al., 2008; Krzyzanowski, 2008; Brook et al., 2009; Mohai et al., 2011).

Nowadays, air pollution is an international problem with several impacts on living organisms (Akimoto, 2003). Many open questions still remain, such as the measurement and monitoring of air pollution, including the exploration of new technologies and methods like remote sensing and in-situ observations. For example, the investigation of air pollution over megacities by means of satellites observations has recently become a central topic of interest within the air pollution community (Van der A et al., 2008; Kar et al., 2010; Xue et al., 2010; Hilboll et al., 2013). Air pollution also impacts historic and modern buildings and materials, affecting sites of cultural heritage by damaging structural materials of monuments, statues, and even paintings. For example, substances such as sulfur dioxide, nitrogen compounds, ozone, and particulates can lead to material corrosion (Tzanis et al., 2011).

In addition, it is of great importance to collect new data on hazardous and toxic substances, gaseous and particulate air pollutants. Among the two hundred toxic air pollutants, particular interest needs to be paid to those that are prevalent in specific regions, such as benzene and formaldehyde in the United States (Suh et al., 2000; Osthoff et al., 2008).

Both, indoor and outdoor air pollution has been found to cause serious health effects, such as respiratory problems, including asthma, human eye, and skin irritation, and others. To this day, however, the effects of bioaerosol pollution at the workplace and at home remain unclear (Ziemke et al., 2000; Trasande and Thurston, 2005; Bernstein et al., 2008).

New algorithms are being developed for the association of air pollution to other geophysical parameters such as solar and terrestrial radiation field in order to study the interplay of air pollution with long- and shortwave radiation. As an example, the solar radiation reaching the Earth's surface affects the terrestrial environment, thus changes in air pollution and cloudiness may substantially affect atmospheric transmission leading to a decline (dimming effect) or increase (brightening effect) in solar irradiance at the surface. These changes may significantly affect surface climate and consequently, the state of ecosystems (Wild et al., 2005).

To investigate the spatio-temporal variability of air pollution on a local, regional, and global scale, new tools are being developed. In this context, the detection, tracking and understanding of pollutant transport on various spatial scales are of both local and global interest. Specifically, in rural and remote areas, where no ground-based monitoring network of the air pollution is available, the use of satellite data can provide an estimation of the regional distribution of pollutants, in order to assess the impact of specific events (e.g., biomass burning or dust storm outbreaks) (Lee et al., 2007). Over the last decade the role of the non-linear dynamics to the spatio-temporal variability of air pollution has still not been resolved (Varotsos, 2005; Varotsos et al., 2012, 2013). Air pollution, as most geophysical properties such as air turbulence, air temperature, humidity, precipitation, and ozone, obeys non-linear laws, which usually generate spatio-temporal, nonstationarities and thus instead of the application of the conventional analyses (i.e., Fourier analysis), new analytical techniques (i.e., detrended fluctuation analysis) capable to eliminate the nonstationarities in the data should be utilized.

The role of air pollution in climate change dynamics is a question that must be urgently addressed. For example, the importance of air pollution and greenhouse warming vs. aerosol cooling needs to be discussed with air pollution cooling, dominated by aerosol content, expected to decline relative to greenhouse gas forcing in the future. The main reason is a much shorter lifetime of aerosols compared to that of most greenhouse gases (Andreae et al., 2005).

In order to improve air pollution modeling and mitigation, modern research should take into consideration the implications of alternative formulations of air pollution modeling as well as integrated assessment models for further mitigation measures (Varotsos and Kirk-Davidoff, 2006; Amann et al., 2011). Current and future air pollution and ozone variability 
in the troposphere and stratosphere need to be addressed. For example, the recognition of the stratospheric ozone depletion and the increase of the tropospheric ozone amount has led to intensive theoretical and experimental research of the ozonesphere over the last three decades. Nevertheless, important problems still remain and need to be urgently addressed, including the non-linear behavior of the relevant chemical and dynamical mechanisms.

In conclusion, the aforementioned priorities in air pollution research combined with the social implications, such as the effects on vegetation, soil and water (Serengil et al., 2011) require the improvement and development of policy measures, as well as prevention and control regulations (Van der Sluijs et al., 2008). Shedding new light on the above aspects will drive the work of Frontiers in Air Pollution.

\section{REFERENCES}

Akimoto, H. (2003). Global air quality and pollution. Science 302, 1716-1719. doi: 10.1126/science.1092666

Amann, M., Bertok, I., Borken-Kleefeld, J., Cofala, J., Heyes, C., Höglund-Isaksson, L., et al. (2011). Cost-effective control of air quality and greenhouse gases in Europe: modeling and policy applications. Environ. Model. Softw. 26, 1489-1501. doi: 10.1016/j.envsoft.2011.07.012

Andreae, M. O., Jones, C. D., and Cox, P. M. (2005). Strong present-day aerosol cooling implies a hot future. Nature 435, 1187-1190. doi: 10.1038/nature03671

Ayers, G. (2005). Air pollution and climate change: has air pollution suppressed rainfall over Australia? Clean Air Environ. Qual. 39, 51-57.

Bernstein, J. A., Alexis, N., Bacchus, H., Bernstein, I. L., Fritz, P., Horner, E., et al. (2008). The health effects of nonindustrial indoor air pollution. J. Allergy Clin. Immunol. 121, 585-591. doi: 10.1016/j.jaci.2007.10.045

Brook, R. D., Urch, B., Dvonch, J. T., Bard, R. L., Speck, M., Keeler, G., et al. (2009). Insights into the mechanisms and mediators of the effects of air pollution exposure on blood pressure and vascular function in healthy humans. Hypertension 54, 659-667. doi: 10.1161/HYPERTENSIONAHA.109.130237

Dockery, D. W., and Stone, P. H. (2007). Cardiovascular risks from fine particulate air pollution. N. Eng. J. Med. 356, 511-513. doi: 10.1056/NEJMe068274

Fullerton, D. G., Bruce, N., and Gordon, S. B. (2008). Indoor air pollution from biomass fuel smoke is a major health concern in the developing world.
Trans. R. Soc. Trop. Med. Hyg. 102, 843-851. doi: 10.1016/j.trstmh.2008.05.028

Hilboll, A., Richter, A., and Burrows, J. P. (2013). Long-term changes of tropospheric $\mathrm{NO} 2$ over megacities derived from multiple satellite instruments. Atmos. Chem. Phys. 13, 4145-4169. doi: 10.5194/acp-13-4145-2013

Kar, J., Fishman, J., Creilson, J. K., Richter, A., Ziemke, J., and Chandra, S. (2010). Are there urban signatures in the tropospheric ozone column products derived from satellite measurements. Atmos. Chem. Phys. 10, 5213-5222. doi: 10.5194/acp-105213-2010

Kelly, F. J. (2003). Oxidative stress: its role in air pollution and adverse health effects. Occup. Environ. Med. 60, 612-616. doi: 10.1136/oem.60.8.612

Krzyzanowski, M. (2008). WHO air quality guidelines for Europe. J. Toxicol. Environ. Health Part A 71, 47-50. doi: 10.1080/15287390701557834

Lee, K. H., Kim, Y. J., von Hoyningen-Huene, W. and Burrow, J. P. (2007). Spatio-temporal variability of satellite-derived aerosol optical thickness over Northeast Asia in 2004. Atmos. Environ. 41, 3959-3973. doi: 10.1016/j.atmosenv.2007. 01.048

Miller, K. A., Siscovick, D. S., Sheppard, L., Shepherd, K., Sullivan, J. H., Anderson, G. L., et al. (2007). Long-term exposure to air pollution and incidence of cardiovascular events in women. N. Eng. J. Med. 356, 447-458. doi: 10.1056/NEJMoa054409

Mohai, P., Kweon, B. S., Lee, S., and Ard, K. (2011). Air pollution around schools is linked to poorer student health and academic performance. Health Aff. 30, 852-862. doi: 10.1377/hlthaff.2011.0077

Osthoff, H. D., Roberts, J. M., Ravishankara, A. R., Williams, E. J., Lerner, B. M., Sommariva, R., et al. (2008). High levels of nitryl chloride in the polluted subtropical marine boundary layer. Nat. Geosci. 1, 324-328. doi: 10.1038/ ngeo177

Schwartz, J. (2004). Air pollution and children's health. Pediatrics 113(Suppl. 3), 1037-1043.

Serengil, Y., Augustaitis, A., Bytnerowicz, A., Grulke, N., Kozovitz, A. R., Matyssek, R., et al. (2011). Adaptation of forest ecosystems to air pollution and climate change: a global assessment on research priorities. Forest Biogeosci. Forest. 4, 44. doi: 10.3832/ifor0566-004

Suh, H. H., Bahadori, T., Vallarino, J., and Spengler J. D. (2000). Criteria air pollutants and toxic air pollutants. Environ. Health Perspect. 108(Suppl. 4), 625. doi: $10.2307 / 3454398$

Trasande, L., and Thurston, G. D. (2005). The role of air pollution in asthma and other pediatric morbidities. J. Allergy Clin. Immunol. 115, 689-699. doi: 10.1016/j.jaci.2005.01.056

Tzanis, C., Varotsos, C., Christodoulakis, J., Tidblad, J., Ferm, M., Ionescu, A., et al. (2011). On the corrosion and soiling effects on materials by air pollution in Athens, Greece. Atmos. Chem. Phys. 11, 12039-12048. doi: 10.5194/acp-11-12039-2011

Van der A, R. J., Eskes, H. J., Boersma, K. F., van Noije, T. P. C., Van Roozendael, M., De Smedt, I., et al.
(2008). Trends, seasonal variability and dominant NO $\mathrm{x}$ source derived from a ten year record of NO 2 measured from space. J. Geophys. Res. 113, D04302. doi: 10.1029/2007JD009021

Van der Sluijs, J. P., Petersen, A. C., Janssen, P. H., Risbey, J. S., and Ravetz, J. R. (2008). Exploring the quality of evidence for complex and contested policy decisions. Environ. Res. Lett. 3, 024008. doi: 10.1088/1748-9326/3/2/024008

Varotsos, C. (2005). Power-law correlations in column ozone over Antarctica. Int. J. Remote Sens. 26, 3333-3342. doi: 10.1080/01431160500076111

Varotsos, C., and Kirk-Davidoff, D. (2006). Longmemory processes in ozone and temperature variations at the region $60 \mathrm{~S}-60 \mathrm{~N}$. Atmos. Chem. Phys. 6, 4093-4100. doi: 10.5194/acp-6-4093-2006

Varotsos, C. A., Melnikova, I., Efstathiou, M. N., and Tzanis, C. (2013). 1/f noise in the UV solar spectral irradiance. Theor. Appl. Climatol. 111, 641-648. doi: 10.1007/s00704-012-0697-8

Varotsos, C., Ondov, J., Tzanis, C., Öztürk, F., Nelson, M., Ke, H., et al. (2012). An observational study of the atmospheric ultra-fine particle dynamics. Atmos. Environ. 59, 312-319. doi: 10.1016/j.atmosenv.2012.05.015

Wild, M., Gilgen, H., Roesch, A., Ohmura, A., Long, C. N., Dutton, E. G., et al. (2005). From dimming to brightening: Decadal changes in solar radiation at Earth's surface. Science 308, 847-850. doi: 10.1126/science. 1103215

Wilson, N., Edwards, R., Maher, A., Näthe, J., and Jalali, R. (2007). National smoke free law in New Zealand improves air quality inside bars, pubs and restaurants. BMC Public Health 7:85. doi: 10.1186/1471-2458-7-85

Xue, Y., Ai, J., Wan, W., Li, Y., Wang, Y., Guang, J., et al. (2010). Workload and task management of grid- enabled quantitative aerosol retrieval from remotely-sensed data. Future Generation Comput. Syst. 20, 590-598. doi: 10.1016/j.future.2009.11.003

Ziemke, J. R., Chandra, S., Herman, J., and Varotsos, C. (2000). Erythemally weighted UV trends over northern latitudes derived from Nimbus 7 TOMS measurements. J. Geophys. Res. 105, 7373-7382. doi: 10.1029/1999JD901131

Received: 24 October 2013; accepted: 05 November 2013; published online: 26 November 2013.

Citation: Varotsos CA (2013) The grand challenges to air pollution. Front. Environ. Sci. 1:3. doi: 10.3389/ fenvs. 2013.00003

This article was submitted to Air Pollution, a section of the journal Frontiers in Environmental Science.

Copyright $\odot 2013$ Varotsos. This is an open-access article distributed under the terms of the Creative Commons Attribution License (CC BY). The use, distribution or reproduction in other forums is permitted, provided the original author(s) or licensor are credited and that the original publication in this journal is cited, in accordance with accepted academic practice. No use, distribution or reproduction is permitted which does not comply with these terms. 